\title{
AVALIAÇÃo dE MELÃo MiNiMAMENTE PROCESSADO ARMAZENADO EM DIFERENTES TEMPERATURAS E EMBALAGENS ${ }^{1}$
}

\author{
Cintya Alejandra CASTILHO PIZARRO², Benedito Carlos BENEDETTI ${ }^{3, *}$, \\ Niurka Maritza Almeyda HAJ-ISA,*
}

\begin{abstract}
RESUMO
Os produtos minimamente processados oferecem diversos benefícios para o consumidor, entre os quais destacam-se a redução do tempo de preparação dos alimentos, a oferta de produtos saudáveis com excelente qualidade e a necessidade de menor espaço para seu armazenamento. Este trabalho teve por objetivo avaliar qual embalagem (tereftalato de poliestireno ou bandeja de poliestireno expandido com cobertura de policloreto de vinila) seria mais adequada para o armazenamento de melão minimamente processado, armazenado nas temperaturas de $4^{\circ} \mathrm{C}$ e $10^{\circ} \mathrm{C}$. Os frutos passaram pelo processo mínimo que consistiu em: recepção, seleção, lavagem com água corrente, lavagem com solução de hipoclorito de sódio (200 mg.L $\left.\mathrm{L}^{-1} / 15 \mathrm{~min}\right)$, resfriamento $10^{\circ} \mathrm{C} / 24 \mathrm{~h}$, descasque e corte manual (fatia), banho de imersão em solução de hipoclorito de sódio ( $40 \mathrm{mg} . \mathrm{L}^{-1} / 30 \mathrm{~s}$ ), embalagem e armazenamento. Aos $0,3,5,7$ e 10 dias de armazenamento foram feitas análises da concentração de $\mathrm{O}_{2}$ e $\mathrm{CO}_{2}$, firmeza, pH, acidez total titulável, sólidos solúveis totais, açúcares totais e redutores e avaliação sensorial com provadores treinados. Os resultados mostraram que houve diferenças significativas ao longo do armazenamento no teor de $\mathrm{O}_{2} \mathrm{e} \mathrm{CO}_{2}$, firmeza, $\mathrm{pH}$, açúcares totais e redutores. Quando comparados com os demais tratamentos, as características das frutas armazenadas em embalagens de tereftalato de polietileno a $4^{\circ} \mathrm{C}$ mantiveramse mais estáveis. $\mathrm{Na}$ análise sensorial houve diferença significativa entre o primeiro dia de análise e os demais, mostrando que o melão minimamente processado diminui sua qualidade sensorial ao longo do tempo.

Palavras-chave: melão, processamento mínimo, embalagem, armazenamento, análise sensorial.
\end{abstract}

\section{SUMMARY}

EVALUATION OF MINIMALLY PROCESSED MELON STORED AT DIFFERENT TEMPERATURES AND PACKAGES. The minimally processed products offer several benefits for consumers, such as the reduction of the time for food preparation, the purchase of healthy products with excellent quality and smaller space for their storage. The objective of this work was to evaluate which package (polyethylene terephtalate or expanded polyestiren tray covered with polyvinyl chloride) would be better for the storage of minimally processed melon stored at $4^{\circ} \mathrm{C}$ and $10^{\circ} \mathrm{C}$. The fruits had passed for the minimum process, which consisted in: reception, selection, washing with tap water and with $200 \mathrm{mg} \cdot \mathrm{L}^{-1}$ sodium hypochlorote solution, cooling at $10^{\circ} \mathrm{C} / 24 \mathrm{~h}$, peeling and manual cut (slice), immersion bath with $40 \mathrm{mg}$. $\mathrm{L}^{-1}$ sodium hypochlorote solution for $30 \mathrm{~s}$, packing and storage. Analyses of $\mathrm{O}_{2}$ and $\mathrm{CO}_{2}$ concentrations, firmness, $\mathrm{pH}$, total acidity, total solid soluble, total and reducing sugars, and sensorial analysis had been made at $0,3,5,7$ and 10 days of storage. The results show that there were significant differences during the storage period for $\mathrm{O}_{2}$ and $\mathrm{CO}_{2}$ concentration, firmness, $\mathrm{pH}$, total and reducing sugars. The characteristics of the fruits stored in polyethylene terephtalate packages at $4^{\circ} \mathrm{C}$ remained more steady when compared with the other treatments. In the sensorial analysis it had significant difference between the first day and the others, showing that the minimally processed melon decreases its sensorial quality with the time.

Keywords: melon, fresh-cut, package, storage, sensorial analysis.

\section{1 - INTRODUÇÃO}

O Brasil é o terceiro maior produtor de melão da América Latina. O País passou de importador a grande produtor e, posteriormente, a exportador para os mercados europeus e norte-americano, sendo que cerca de $20 \%$ da produção nacional é destinada à exportação. A Região Nordeste responde por $97,70 \%$ da produção nacional [1]. Com relação à exportação, foi altamente significativo o incremento do consumo do melão no mercado europeu, sendo que a União Européia é hoje o principal importador do Brasil, absorven-

\footnotetext{
${ }^{1}$ Recebido para publicação em 4/2/2004. Aceito para publicação em 28/04/2006 (001281)

${ }^{2}$ Universidade Estadual de Campinas, Faculdade de Engenharia Agrícola, Caixa Postal 6011, CEP 13083-970, Campinas (SP). E-mail: cintya@agr.unicamp.br

${ }^{3}$ Universidade Estadual de Campinas, Faculdade de Engenharia Agrícola, Caixa Postal 6011, CEP 13083-970, Campinas (SP). E-mail:benedeti@agr.unicamp.br

${ }^{4}$ Fundação de Ensino Superior de Bragança Paulista (Fesb), Caixa Postal 183, CEP 12929-600, Bragança Paulista (SP). E-mail:niurka_hajisa@hotmail.com

*A quem a correspondência deve ser enviada
}

do, aproximadamente, $90 \%$ das nossas exportações dessa fruta, com mais de 600 mil toneladas anuais [2].

No Brasil, a tecnologia de processamento mínimo de frutos e hortaliças foi introduzida na década de 90, encontrando-se em franca expansão, visando principalmente os serviços de fornecimento de alimentos prontos para o consumo, como cadeias de fast food, hotéis, restaurantes, lanchonetes e redes de supermercado. A tendência aponta para a especialização cada vez maior, com aumento na variedade de produtos e total direcionamento para o consumidor, tanto no varejo quanto para o mercado institucional [8].

O processo mínimo de hortaliças é uma prática relativamente recente, que promete contribuir com a redução dos desperdícios e, como conseqüência, para a substancial economia de alimentos em nosso País. Assim, pode-se sintetizar as vantagens para os consumidores de produtos minimamente processados (MP): maior praticidade no preparo dos alimentos; reduzido desperdício devido ao descarte de partes indesejáveis; maior segurança na aquisição de produtos limpos e embalados, possibilidade da compra de menores quantidades, possibilidade de conhecer a procedência do produto e de escolher marcas [14]. 
Embora a grande maioria dos estudos realizados nesta área esteja relacionada ao processamento mínimo de produtos olerícolas, constata-se o grande potencial de comercialização de frutos minimamente processados, principalmente aqueles que oferecem, em função de sua própria estrutura, alguma dificuldade para a comercialização ou até mesmo para consumo [9].

O processo mínimo inclui seleção, lavagem, desinfecção, remoção da casca e corte, em formas e tamanhos que variam em função da natureza do produto não-processado e do hábito de consumo, assim como embalagem e refrigeração. Os objetivos do processo são conservar a qualidade visual e nutricional dos produtos, agregar valor ao produto agrícola e facilitar a vida dos consumidores [6, 16].

Segundo YILDIZ [17], a ampliação da classe de produtos MP encontra-se restrita, devido à escassez de informações e pesquisas em relação ao comportamento fisiológico e a conservação pós-colheita, assim como quanto à adequação de embalagens específicas a cada tipo de produto. $\mathrm{O}$ melão, apesar de não ser encontrado em grande escala e com freqüência no mercado na forma de MP, apresenta grande potencial [12]. Entre os consumidores de produtos MP, de 21 a $36 \%$ já consomem o melão nesta forma de apresentação [11].

Este trabalho teve por objetivo avaliar qual embalagem (tereftalato de polietileno - PET ou bandeja de polietileno expandido com cobertura de policloreto de vinila - PVC) seria mais adequada para o armazenamento de melão minimamente processado, armazenado nas temperaturas de $4^{\circ} \mathrm{C}$ e $10^{\circ} \mathrm{C}$, considerando as alterações na qualidade física, físico-química e sensorial do produto.

\section{2 - MATERIAL E MÉTODOS}

\section{1 - Matéria-prima}

Utilizaram-se nos experimentos melões do grupo Inodorus Amarelo, classificados como tipo 6, procedentes de Assu/Mossoró, Estado do Rio Grande do Norte. Estes frutos foram transportados durante quatro dias em caminhão aberto, sem refrigeração, até a Ceasa/Campinas. Foram adquiridas caixas de $13 \mathrm{~kg}$, com frutos maduros, firmes e apresentando aproximadamente $75 \%$ da casca amarela, que foram transportados para o laboratório de Tecnologia Pós-Colheita da Feagri/Unicamp, onde o experimento foi realizado.

\section{2 - Etapa preliminar}

\subsection{1 - Pesquisa com consumidores de melão}

Foi realizado um teste de preferência com 150 consumidores em supermercado de Campinas (SP), para saber qual o tipo de corte no melão (fatia ou cubo) e o tipo de embalagem para comercialização (tereftalato de polietileno ou bandeja de poliestireno expandido com cobertura de policloreto de vinila), que seriam melhor aceitos pelos consumidores. O teste visou também avaliar a freqüência de consumo de melão e qual a finalidade de compra (consumo em fruto ou em suco/vitamina).

Numa bancada colocada na área destinada aos produtos hortifrutigranjeiros do supermercado foram apresentadas as seguintes amostras: melão em formato de cubos em embalagem PET (Cubo/PET); melão em formato de cubos em embalagem PVC (Cubo/PVC); melão em formato de fatias em embalagem PET (Fatia/PET); melão em formato de fatias em embalagem PVC (Fatia/PVC).

\subsection{2 - Conformação e treinamento de painel sensorial}

Para a avaliação de melão MP foi aplicado o método de Análise Descritiva Quantitativa Modificado (ADQm), que avalia apenas os atributos de maior interesse para o tipo de produto e seu impacto na preferência do consumidor [10, 13]. O processo de ADQm constou dos seguintes passos:

\subsubsection{1 - Recrutamento e seleção de candidatos a painelistas}

Foram recrutados e selecionados 28 candidatos levando em consideração o interesse, disponibilidade, pontualidade, saúde, atitude com respeito ao produto e capacidade nas percepções sensoriais (olfato, tato, paladar e visual). Inicialmente, os voluntários foram solicitados a descrever os atributos aparência, aroma, textura no corte e sabor de amostras de melão cortado em fatias. Testes triangulares e de ordenação também foram aplicados. Selecionaram-se todos os candidatos com, no mínimo, $75 \%$ de acerto nos diferentes testes.

\subsubsection{2 - Treinamento}

Esta etapa teve por finalidade familiarizar os provadores com: o produto, suas características e possíveis mudanças durante o armazenamento, o método de avaliação, a elaboração das fichas sensoriais, a melhora da memória sensorial e a consistência dos mesmos nas avaliações.

Inicialmente, foi desenvolvido, consensualmente, o vocabulário descritivo e determinados os extremos da escala não estruturada $(9 \mathrm{~cm})$ para cada atributo a ser avaliado no melão MP. Os atributos brilho, aroma, textura no corte e sabor foram consensualmente determinados como os mais importantes. Para produzir variações nesses atributos, amostras de melão MP sofreram diferentes tratamentos (enxágüe com água e tratamentos com solução de $\mathrm{NaOCl} 40$ e $60 \mathrm{mg} . \mathrm{L}^{-1}$,). Ainda foi necessário para criar as referências dos extremos das escalas de cada descritor, aplicar outros tratamentos nas amostras.

Para o brilho, secou-se uma fatia de melão com papel toalha deixando-a totalmente opaca, definindo esta como extremo inferior da escala (menos brilho), enquanto outra fatia foi imersa em água deixando-a brilhante, definindo o extremo superior da escala (mais brilho) e sendo o centro da escala representado por uma fatia sem tratamento. $\mathrm{Na}$ definição da textura de corte e sabor foram utilizados melões verdes, maduros e passados. Para a textura, colocou-se o 
melão verde como extremo da escala mais firme, o maduro como centro e o passado como extremo de menos firme. Na escala da doçura, colocou-se o melão "de vez" como extremo menos adocicado, maduro como centro da escala e o passado como extremo da escala de mais adocicado. Após apresentar estes tratamentos aos julgadores, os mesmos testes anteriormente citados foram repetidos, porém agora tendo as referências dos extremos das escalas.

Os provadores foram selecionados com base em suas habilidades discriminativas, reprodutibilidade dos julgamentos e consenso com a equipe, de acordo com STONE \& SIDEL [16].

\section{3 - Processo mínimo}

Chegando ao laboratório, os frutos foram selecionados descartando-se os que apresentavam injúrias mecânicas e podridões. Em seguida foram submetidos à lavagem com água corrente e sabão próprio para limpeza de frutos (Sumaveg), drenados por 3 min em grades e armazenados em geladeira a $10^{\circ} \mathrm{C} / 48 \mathrm{~h}$, para reduzir a temperatura interna do fruto, até o dia do processamento. A sala e os equipamentos utilizados no processamento foram sanitizados para diminuir possíveis contaminações. Os equipamentos como balança, engradados, grades para drenagem e seladora foram sanitizados com solução de $\mathrm{NaOCl}$ a $1000 \mathrm{mg} \cdot \mathrm{L}^{-1}$. Os demais equipamentos como facas, tábuas de corte e bandejas foram sanitizados com solução de $\mathrm{NaOCl}$ a $200 \mathrm{mg} \cdot \mathrm{L}^{-1}$, A menor concentração de $\mathrm{NaOCl}$ foi usada para se evitar que o melão MP adquirisse o gosto da solução. A temperatura da sala na hora do processamento foi mantida a $15 \pm 2^{\circ} \mathrm{C}$ com a ajuda de ar condicionado.

Devido aos resultados obtidos na etapa preliminar, no processamento para obtenção dos produtos MP (Figura 1), aplicou-se o corte tipo fatia e as embalagens: 1) tereftalato de polietileno com tampa e capacidade para $750 \mathrm{~mL}$ (PET); 2) bandeja de poliestireno expandido com cobertura de policloreto de vinila de $20 \mu \mathrm{m}$ (PVC).

Em cada embalagem foram colocadas duas fatias de melão, o que representou aproximadamente $150 \mathrm{~g}$ do fruto. Para o armazenamento, foram utilizadas câmaras mantidas nas temperaturas de $4 \pm 2^{\circ} \mathrm{C}$ e $10 \pm 2^{\circ} \mathrm{C}$, durante todo o tempo. A temperatura de $4^{\circ} \mathrm{C}$ foi escolhida por ser considerada ideal para conservação de produtos vegetais MP, e a de $10^{\circ} \mathrm{C}$, por ser a temperatura média geralmente encontrada na maioria das gôndolas de supermercados e refrigeradores domésticos.

Nos dias $0,3,5,7$ e 10 foram realizados análises de firmeza, pH, sólidos solúveis totais, acidez total titulável, açúcares totais, açúcares redutores e avaliação da concentração dos gases $\mathrm{O} 2$ e $\mathrm{CO} 2$ nas embalagens. Os produtos foram avaliados sensorialmente nos dias 0,3 e 5 , porém não foram avaliados nos dias 7 e 10 por se apresentarem microbiologicamente impróprios para o consumo.

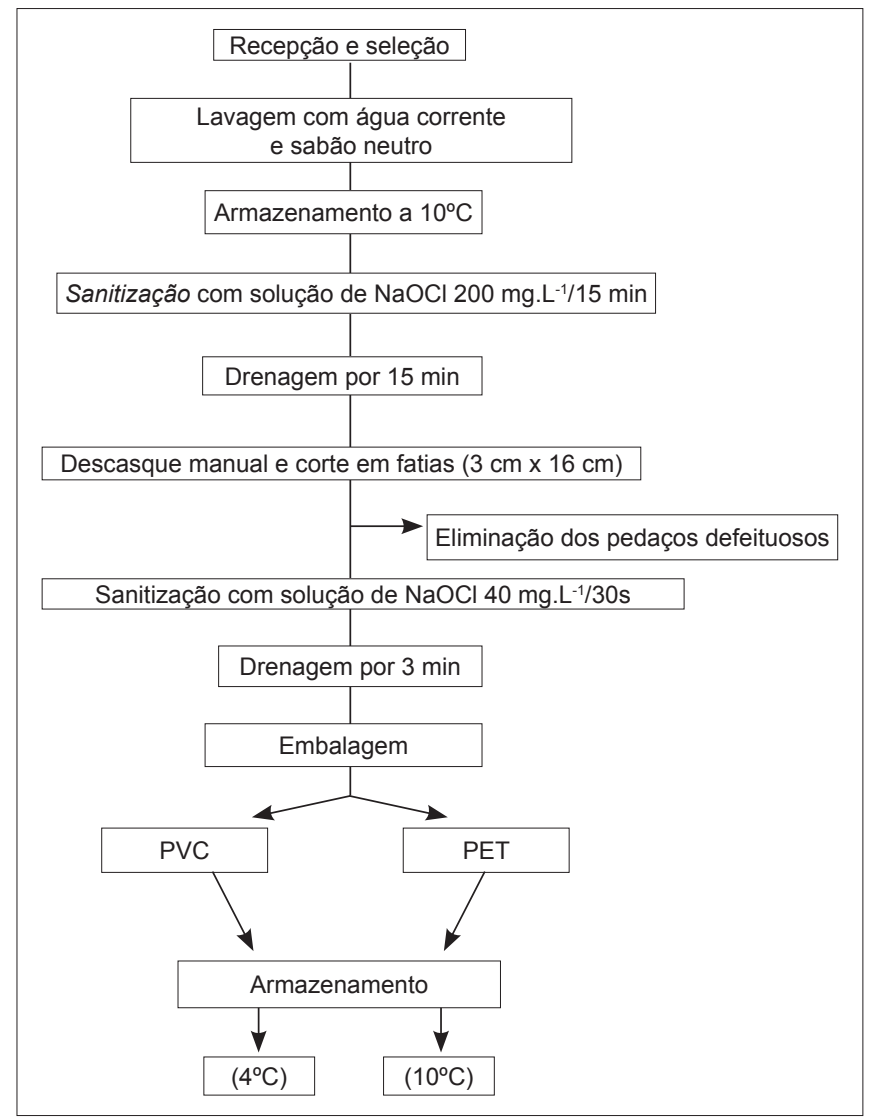

FIGURA 1 - Fluxograma utilizado para o processamento mínimo do melão

\subsection{1 - Delineamento}

O experimento seguiu um delineamento inteiramente casualizado, fatorial $2 \times 2 \times 4$, sendo duas embalagens, duas temperaturas e quatro dias de avaliação. As características avaliadas foram comparadas com as do fruto no dia zero (Tratamento Controle). Para a interpretação dos resultados utilizaram-se as seguintes siglas:

- TC: Tratamento Controle, dia zero;

- PET 4: embalagem plástica de tereftalato de polietileno (PET), armazenada a $4^{\circ} \mathrm{C}$;

- PET 10: embalagem plástica de tereftalato de polietileno (PET), armazenada a $10^{\circ} \mathrm{C}$;

- PVC 4: embalagem bandeja de poliestireno envolta por filme de PVC, armazenada a $4^{\circ} \mathrm{C}$;

- PVC 10: embalagem bandeja de poliestireno envolta por filme de PVC, armazenada a $10^{\circ} \mathrm{C}$;

\subsection{2 - Análises realizadas}

- Composição gasosa: leitura direta da concentração de $\mathrm{O}_{2}$ e $\mathrm{CO}_{2}$ nas embalagens foi feita com o aparelho de marca comercial Mocon;

- Firmeza da polpa: determinada através de penetrômetro manual de frutos modelo Bishop-ST 011, sendo 
os valores de força expressos em Newton. Para cada embalagem, seis medidas foram feitas, sendo três na parte lateral de cada uma das fatias;

- $\quad \mathrm{pH}$ : medido diretamente por potenciometria [7];

- Sólidos solúveis totais (SST): foi utilizado refratômetro manual Abbe Refractometer, modelo 2WAJ, Shangai Optical Instrument Company (Hong Kong), segundo CARVALHO et al. [7];

- Acidez total titulável (ATT): de acordo com CARVALHO et al. [7];

- Açúcares totais e redutores: método volumétrico de Lane \& Eynon, conforme descrito nas normas da AOAC [4];

- $\quad$ Análise sensorial: ADQm com equipe de 11 julgadores parcialmente treinados. As amostras foram apresentadas de maneira monádica e casualizada. Para avaliação do brilho, da textura no corte, o aroma e o sabor; foram utilizadas escalas não estruturadas de $9 \mathrm{~cm}$, ancoradas nos extremos. Nos dias 0,3 e 5, os julgadores analisaram oito amostras (duas por tratamento).

- Análises estatísticas:

- Análises físicas e físico-químicas: teste ANOVA para verificação de diferenças estatísticas e pelo teste de Tukey

- Avaliação sensorial: foram calculadas as médias das notas de duas repetições por cada provador. Os resultados foram avaliados por análise de variância (ANOVA) e pelo teste de Tukey quando diferenças foram detectadas. Os parâmetros de seleção foram: a) capacidade de discriminar as amostras $(\mathrm{p}<0,05)$; b) boa reprodutibilidade $(\mathrm{p}>0,05)$ e; c) resultados consistentes com a equipe.

\section{3 - RESULTADOS E DISCUSSÃO}

\section{1 - Pesquisa com consumidores de melão}

Dos 150 entrevistados, 60\% eram mulheres e $40 \%$ homens, com idade média de 40 anos. Deles, 30\% consomem melão diariamente, $47 \%$ no mínimo uma vez por semana e $23 \%$ ocasionalmente. Verificou-se que $89 \%$ dos participantes compravam o melão MP para consumo in natura, forma preferida na terceira idade, e que $11 \%$ o utilizavam para elaborar suco ou vitamina.

O corte de melão em fatia e seu acondicionamento em embalagem PET formou a combinação melhor aceita pelos consumidores de melão (46\%), quando o produto é minimamente processado; seguida de Cubo/PET (25\%), Fatia/PVC (20\%) e Cubo/PVC (9\%). Grande parte dos entrevistados alegou preferir o corte em fatia, pois os cubos davam impressão de resto de fruto. A embalagem PET foi preferida por ser visualmente mais bonita e poder ser reutilizada. Mesmo que os consumidores escolheram a embalagem PET, no experimento final a embalagem de PVC também foi utilizada, pensando-se no custo mais baixo da embalagem para produtores de pequeno e médio porte.

\section{2 - Composição gasosa no interior das embalagens}

Não houve diferenças estatisticamente significativas $(\mathrm{p} \leq 0,05)$ na concentração de $\mathrm{O}_{2}$ entre os diferentes tratamentos até três dias de armazenamento. No entanto, nos produtos acondicionados em embalagens de PVC valores inferiores foram encontrados quando comparados ao da amostra controle (Dia 0), diferindo estatisticamente, neste aspecto, das embalagens PET.

Durante o período estudado a concentração de $\mathrm{O}_{2}$ medida nas embalagens PET mantidas a $4{ }^{\circ} \mathrm{C}$ manteve-se praticamente constante e sem diferenças $(\mathrm{p} \leq 0,05)$ com a amostra controle. Igual comportamento no tempo foi observado nas embalagens PVC mantidas a $10^{\circ} \mathrm{C}$ porem, nestas, o teor de $\mathrm{O}_{2}$ medido foi sempre significativamente menor que o da amostra controle.

A partir do $5^{\circ}$ dia de armazenamento os valores de $\mathrm{O}_{2}$ medidos em todas as embalagens armazenadas a $10^{\circ} \mathrm{C}$ foram significativamente menores $(\mathrm{p} \leq 0,05)$ quando comparados com as embalagens mantidas a $4^{\circ} \mathrm{C}$ e com a amostra controle.

No $5^{\circ}$ dia de armazenamento foi encontrado, em todos os tratamentos, um teor de $\mathrm{O}_{2}$ inferior aos contabilizados durante todo o estudo (Figura 2), sem que uma explicação clara pudesse ser oferecida. Ao realizar um novo teste de ANOVA eliminando os dados referentes a esse dia, não foram encontradas diferenças estatísticas, em nenhum dos tratamentos, ao longo do tempo, mas apenas entre as embalagens dentro do mesmo dia, confirmando os resultados anteriores.

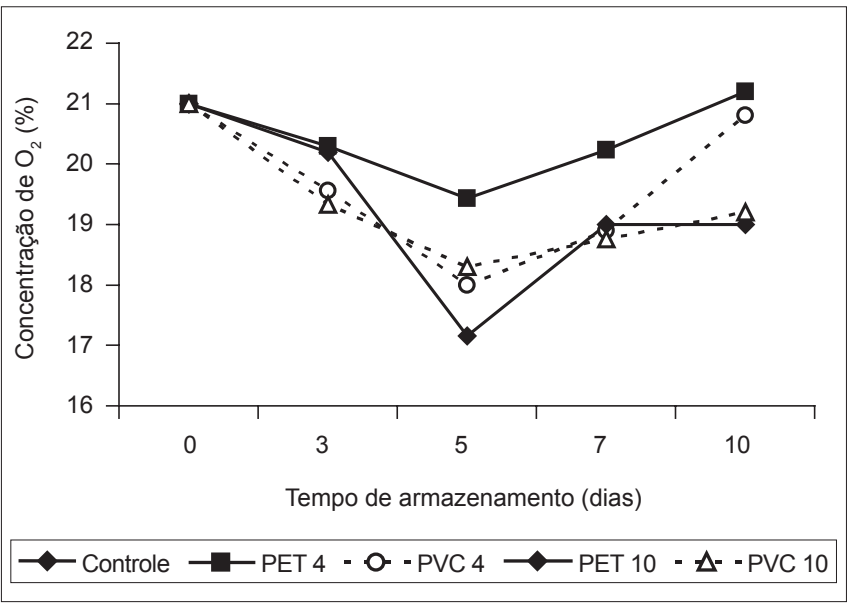

FIGURA 2 - Teor de $\mathrm{O}_{2}$ no interior das embalagens de melão MP

Não houve diferenças significativas $(p \leq 0,05)$ na concentração de $\mathrm{CO}_{2}$ entre os diferentes tratamentos e a amostra-controle durante todo o armazenamento, nem deles com o controle, com exceção do tratamento PET-10, que apresentou variações bruscas que diferiram estatistica- 
mente nos dias 5 e 10, mas sem que possamos explicar os motivos. Ao realizar um novo teste de ANOVA eliminando o dado referente ao dia 7, não foram encontradas diferenças estatísticas entre os dias 5 e 10 para esse tratamento, mas sim, dele com os outros após três dias de armazenamento contendo uma maior concentração de $\mathrm{CO}_{2}$.

\section{3 - Firmeza}

A maioria dos frutos está sujeita à perda substancial da firmeza da polpa durante o amadurecimento e o armazenamento. O mecanismo que controla o amolecimento do melão não tem sido claramente definido [3].

Pesquisas que avaliaram a firmeza de cubos de melão mostraram que amostras de melão MP submetidas a diferentes tratamentos não sofreram amaciamento, no período estudado [5, 14]. Neste trabalho também não foram encontradas diferenças significativas, ao nível de $5 \%$, quando comparados os tratamentos e estes com o controle ao longo dos dias.

\section{4 - Sólidos solúveis totais (SST)}

Ao nível de 5\% não foram encontradas diferenças significativas na variável SST quando comparados os tratamentos com controle, nem entre eles, durante o período avaliado. Estes resultados coincidem com os encontrados por STAMFORD et al. [15], que observaram melóes armazenados a 4 e $15^{\circ} \mathrm{C}$, durante 15 dias, período em que não sofreram alteração no teor de SST. PORTELA \& CANTWELL [13] relataram que a variação de SST em diversas variedades de melóes MP armazenados por 12 dias não foi significativa.

\section{$3.5-\mathrm{pH}$}

Estatisticamente, não foram encontras diferenças significativas $(\mathrm{p} \leq 0,01)$ entre os tratamentos, nem entre eles e o controle ao longo do tempo de prateleira avaliado (Tabela 1). No entanto, a interpretação destes resultados deve ser cuidadosa uma vez que pequenas variações do $\mathrm{pH}$ em produtos MP se correspondem com importantes deteriorações bioquímicas e podem ser sinais de contaminação microbiana.

TABELA 1 - Médias dos valores de pH em melão minimamente processado e acondicionado em diferentes embalagens e armazenados a distintas temperaturas

\begin{tabular}{lcccccc}
\hline & & \multicolumn{5}{c}{ Tempo de armazenamento (dias) } \\
\cline { 3 - 7 } Embalagem & $\mathbf{T}\left({ }^{\circ} \mathbf{C}\right)$ & $\mathbf{0}$ & $\mathbf{3}$ & $\mathbf{5}$ & $\mathbf{7}$ & $\mathbf{1 0}$ \\
\hline Controle & 27,6 & 5,5 & - & - & - & - \\
PET & 4 & - & 5,6 & 5,4 & 5,3 & 5,4 \\
PVC & 4 & - & 5,4 & 5,4 & 5,5 & 5,3 \\
PET & 10 & - & 5,5 & 5,4 & 5,4 & 5,0 \\
PVC & 10 & - & 5,7 & 5,4 & 6,0 & 5,5 \\
\hline
\end{tabular}

\section{6 - Acidez total titulável (ATT)}

Na sua pesquisa, STAMFORD et al. [15] não verificaram alterações significativas nos valores de ATT em melões MP ao longo do armazenamento. Os resultados deste trabalho coincidem com os obtidos por esses autores, pois não foram encontradas diferenças significativas ao nível de $5 \%$, entre os tratamentos nem destes com o controle ao longo do armazenamento.

\section{7 - Açúcares totais e redutores}

O teor de açúcares totais não diferiu entre os tratamentos, mas diferenças estatisticamente significativas ( $\mathrm{p} \leq 0,05)$, foram encontradas durante o tempo de armazenamento ao comparar os produtos com o controle (Tabela 2). Observou-se queda na concentração de açúcares do dia 3 para o dia 5 e, a partir daí, um aumento para todos os tratamentos. Em experimento realizado por ARAUJO et al. [3] obteve-se que o teor de açúcares totais aumentou significativamente a partir do $4^{\circ}$ dia de armazenamento de melão minimamente processado.

Não houve diferenças estatisticamente significativas na variável açúcares redutores entre os tratamentos ao longo do tempo, nem destes com o controle, com exceção dos tratamentos PET 4 e PVC 4 os quais, no $3^{\circ}$ dia de armazenamento, apresentaram níveis mais altos de açúcares redutores se diferenciando do controle e, apenas o tratamento PET 4, mostrou-se diferente das outras condições testadas (Tabela 3). Estas variações podem ser devidas às transformações bioquímicas durante $o$ amadurecimento e senescência do fruto quando ocorre ativação de enzimas catabólicas, interconversão de açúcares, degradação de amido.

TABELA 2 - Resultados do teste de Tukey para valores médios de açúcares totais (g/100 g) ao longo do armazenamento do melão MP acondicionado em diferentes embalagens

\begin{tabular}{lcccccc}
\hline \multirow{2}{*}{ Embalagem } & $\mathbf{T}\left({ }^{\circ} \mathbf{C}\right)$ & \multicolumn{5}{c}{ Tempo de armazenamento (dias) } \\
\cline { 3 - 7 } & & $\mathbf{0}$ & $\mathbf{3}$ & $\mathbf{5}$ & $\mathbf{7}$ & $\mathbf{1 0}$ \\
\hline Controle & 27,6 & $9,91 \mathrm{~b}$ & - & - & - & - \\
PET & 4 & - & $10,79 \mathrm{~b}$ & $7,89 \mathrm{c}$ & $8,68 \mathrm{c}$ & $13,79 \mathrm{a}$ \\
PVC & 4 & - & $10,82 \mathrm{~b}$ & $7,26 \mathrm{c}$ & $9,33 \mathrm{~b}$ & $11,91 \mathrm{a}$ \\
PET & 10 & - & $10,84 \mathrm{~b}$ & $8,40 \mathrm{~b}$ & $9,45 \mathrm{~b}$ & $13,02 \mathrm{a}$ \\
PVC & 10 & - & $9,53 \mathrm{~b}$ & $7,75 \mathrm{c}$ & $8,32 \mathrm{c}$ & $13,91 \mathrm{a}$ \\
\hline
\end{tabular}

Médias com letras iguais nas linhas não diferem estatisticamente entre $\mathrm{si}(\mathrm{p} \leq 0,05)$

TABELA 3 - Resultados do teste de Tukey para valores médios de açúcares redutores (g/100 g) ao longo do armazenamento do melão MP acondicionado em diferentes embalagens

\begin{tabular}{lcccccc}
\hline \multirow{2}{*}{ Embalagem } & $\mathbf{T}\left({ }^{\circ} \mathbf{C}\right)$ & \multicolumn{5}{c}{ Tempo de armazenamento (dias) } \\
\cline { 3 - 7 } & & $\mathbf{0}$ & $\mathbf{3}$ & $\mathbf{5}$ & $\mathbf{7}$ & $\mathbf{1 0}$ \\
\hline Controle & 27,6 & $4,53 \mathrm{~b}$ & - & - & - & - \\
PET & 4 & - & $6,00 \mathrm{a}$ & $4,72 \mathrm{~b}$ & $5,14 \mathrm{~b}$ & $4,64 \mathrm{~b}$ \\
PVC & 4 & - & $5,32 \mathrm{ab}$ & $4,71 \mathrm{~b}$ & $5,09 \mathrm{~b}$ & $4,56 \mathrm{~b}$ \\
PET & 10 & - & $5,06 \mathrm{~b}$ & $4,66 \mathrm{~b}$ & $5,80 \mathrm{~b}$ & $4,99 \mathrm{~b}$ \\
PVC & 10 & - & $5,04 \mathrm{~b}$ & $4,72 \mathrm{~b}$ & $5,04 \mathrm{~b}$ & $4,59 \mathrm{~b}$ \\
\hline Médias com letras iguais nas linhas não diferem estatisticamente entre si (p<0,05)
\end{tabular}




\section{8 - Análise sensorial}

Não houve diferenças estatisticamente significativas, ao nível de $5 \%$, nos atributos brilho e aroma entre os diferentes tratamentos até o quinto dia de armazenamento, mas todas as amostras obtiveram notas sensoriais estatisticamente mais baixas em comparação com o controle (Tabela 4).

Igual avaliação foi feita para o atributo textura no corte com exceção do tratamento PVC 10 aos três dias de armazenamento cuja nota foi igual à do controle. Conforme critério da equipe sensorial, as fatias de melão MP ficaram menos firmes a partir do $5^{\circ}$ dia de armazenamento em todos os tratamentos, menos no PVC 4.

TABELA 4 - Resultados do teste de Tukey com as médias obtidas na análise sensorial do melão minimamente processado

\begin{tabular}{lccccc}
\hline \multirow{2}{*}{$\begin{array}{l}\text { Tempo de } \\
\text { armazenamento } \\
\text { (dias) }\end{array}$} & Tratamentos & \multicolumn{5}{c}{ Atributos sensoriais } \\
\cline { 3 - 6 } & & Brilho & Aroma & $\begin{array}{c}\text { Textura } \\
\text { no corte }\end{array}$ & Sabor \\
\hline 0 & Controle & $6,7 \mathrm{a}$ & $5,6 \mathrm{a}$ & $6,4 \mathrm{a}$ & $6,4 \mathrm{ab}$ \\
\hline \multirow{4}{*}{3} & PET 4 & $4,1 \mathrm{~b}$ & $3,4 \mathrm{~b}$ & $4,9 \mathrm{~b}$ & $6,9 \mathrm{a}$ \\
& PET 10 & $3,6 \mathrm{~b}$ & $3,0 \mathrm{~b}$ & $4,9 \mathrm{~b}$ & $6,0 \mathrm{ab}$ \\
& PVC 4 & $3,7 \mathrm{~b}$ & $3,1 \mathrm{~b}$ & $5,3 \mathrm{~b}$ & $5,7 \mathrm{ab}$ \\
& PVC 10 & $4,1 \mathrm{~b}$ & $3,4 \mathrm{~b}$ & $6,0 \mathrm{a}$ & $6,3 \mathrm{ab}$ \\
\hline \multirow{4}{*}{5} & PET 4 & $4,3 \mathrm{~b}$ & $3,8 \mathrm{~b}$ & $4,6 \mathrm{~b}$ & $5,4 \mathrm{~b}$ \\
& PET 10 & $3,8 \mathrm{~b}$ & $3,7 \mathrm{~b}$ & $4,3 \mathrm{~b}$ & $5,6 \mathrm{~b}$ \\
& PVC 4 & $4,3 \mathrm{~b}$ & $3,5 \mathrm{~b}$ & $4,8 \mathrm{~b}$ & $5,6 \mathrm{~b}$ \\
& PVC 10 & $4,3 \mathrm{~b}$ & $3,7 \mathrm{~b}$ & $4,3 \mathrm{~b}$ & $5,5 \mathrm{~b}$ \\
\hline
\end{tabular}

Médias com letras iguais nas colunas (a cada dia) não diferem significativamente entre si $(\mathrm{p} \leq 0,05)$

Até o terceiro dia de armazenamento todas as amostras de melão minimamente processado, independentemente da embalagem e temperatura em que foram acondicionados, mantiveram o sabor igual ao da amostra controle $(\mathrm{p} \leq 0,05)$.

Estes resultados eram esperados, pois o conjunto de degradações químicas e bioquímicas que tem lugar no fruto leva à ruptura de células e ao aumento da maciez do produto, em função do tempo. Do mesmo modo todos os outros atributos sensoriais são afetados.

\section{4 - CONCLUSÕES}

Na opinião dos consumidores, o corte tipo fatia é o melhor para o processo mínimo de melão. Os resultados obtidos na análise físico-química e sensorial sugerem que o acondicionamento das fatias de melão em embalagens PET e seu armazenamento sob $4^{\circ} \mathrm{C}$ são as condições mais indicadas para a preservação das características das frutas por até três dias.

Após cinco dias de armazenamento, as análises mostraram que não houve superioridade de qualquer dos tratamentos estudados para melhor manter as características do melão minimamente processado, sendo este o prazo máximo para sua aceitação sensorial.

\section{5 - REFERÊNCIAS BIBLIOGRÁFICAS}

[1] ANUÁRIO ESTATÍSTICO DO BRASIL. Rio de Janeiro: IBGE, v. 6, 2000.

[2] ARAUJO, J.L.P. Mercado de melão na Europa. http://www.cpatsa.embrapa.br/artigos/melaoeuropa. html. Acesso em: 14 abr. 2003.

[3] ARAUJO, F.M.M.C; MACHADO, A.V.; CHITARRA, A.B. Efeito da atmosfera modificada na conservação do melão Orange flesh minimamente processado. In: XVIII Congresso Brasileiro de Ciência e Tecnologia de Alimentos, Porto Alegre (RS), 2002 (cd-rom).

[4] A.O.A.C. Published by A.O.A.C., Washington, D.C., 1970; LEES, R. - Manual de Analysis de Alimentos, tradução de A.M. Barrado, Editorial Acribia, Zaragoza, Espanha, 1969.

[5] BASTOS, M.S.R.; SOUZA FILHO, M.S.; ALVES, R.E.; FILGUEIRA, H.A.C.; BORGES, M.F. Processamento mínimo de abacaxi e melão. II Encontro Nacional sobre Processamento Mínimo de Frutos e Hortaliças. Viçosa (MG), p. 89-93, 2001.

[6] CARLIN, F.; NGUYEN, C.; HILBERT, G.; CHAMBROY, Y. Modified atmosphere packaging of fresh, "readyto-use" grated carrots in polymeric films. Journal of Food Science, v. 55, n. 4, p. 1.033-1.038, 1990.

[7] CARVALHO, C.R.L. et al., Análises químicas de alimentos. Campinas: Ital, 1990. 121 p. (Manual Técnico).

[8] CHITARRA, M.I.F. Processamento mínimo de frutos e hortaliças. Viçosa: Centro de Produções Técnicas, 1998, p. 88.

[9] DURIGAN, J.F. Fresh-cut: a modernidade. Jaboticabal: Rev. Unesp Rural, n. 9, p. 10-1, 1999.

[10] HAJ-ISA, N.M.A. Adequação da metodologia de avaliação sensorial ao controle de qualidade de gelatina. Getita do Brasil. São Paulo, jul. 2003. 32 p.

[11] LUNA-GUZMÁN, I.; CANTWELL, M.A.; BARRET, D.M. Fresh-cut cantaloupe: effect of $\mathrm{CaCl}_{2}$ dips and heat treatments on firmness and metabolic activity. Postharvest Biology and Technology, v. 17, p. 201213, 1999.

[12] OLIVEIRA, A.C.; SOUZA FILHO, M. DE S.; FIGUEIREDO, R.W.; TEIXEIRA, J.N.; SOUZA NETO, M.A.; ALMEIDA, R.S. Estudo da caracterização físicoquímica do melão 'Cantaloupe' minimamente processado armazenado a $4^{\circ} \mathrm{C}$ sob diferentes tipos de corte. IV Simpósio Latino Americano de Ciência de Alimentos. p. 223, 2001 (Resumo de Palestra).

[13] PORTELA, S.I.A.; CANTWELL, M.A. Quality changes of minimally processed honeydew melons stored in air or controlled atmosphere. Postharvest Biology and Technology, v.1 7, p. 201-213, 1998.

[14] RODRIGUES, G.; ALVES, M.A.; MALUF, W.R. Hortaliças minimamente processadas. Boletim técnico de hortaliças, n. 31, 1 ${ }^{\mathrm{a}}$ ed., jul. 1999.

[15] STAMFORD, T.L.M.; DAMASCENO, K.S.F.C.; MELO, R.G. Efeito da temperatura de armazenamento sobre a qualidade do melão (Cucumis melo L. var. inodorus) minimamente processado. In: XVIII Congresso Brasileiro de Ciência e Tecnologia de Alimentos, Porto Alegre (RS), 2002 (cd-rom).

[16] STONE, H.; SIDEL, J.L. Sensory evaluation practices. Academic Press, Inc. New York, 1985. 
[17] YILDIZ, F. Initial preparation, manipulation and distribution of fruit and vegetables minimally processed and refrigerated. In: WILEY, R. C. Minimally processed refrigerated fruit and vegetables. Chapman \& Hall, New York, $1^{\text {st }}$ ed., p. 25-60, 1996.

\section{6- AGRADECIMENTOS}

Ao Faep/Unicamp pelo auxílio financeiro para execução do projeto de pesquisa. 